\title{
ANALISIS LITERASI BUKU AJAR BAHASA INDONESIA KARYA TITIK HARSIATI, AGUS TRIANTO, DAN E. KOSASIH KELAS VII
}

\author{
Puspita Intan Purnama N., Agus Trianto, dan Gumono \\ Program Studi Pendidikan Bahasa Indonesia \\ Jurusan Pendidikan Bahasa dan Seni \\ FKIP Universitas Bengkulu \\ puspitaintanpurnama70@gmail.com
}

\begin{abstract}
Abstrak
Literesi merupakan kemampuan mengakses informasi, memahami, mengidentifikasi, mengekspresikan, mengkomunikasikan, dan menciptakan suatu karya. Oleh karena itu, berbagai upaya untuk meningkatkan penguasaan literasi sangat diperlukan. Penelitian ini bertujuan untuk memperoleh informasi literasi dalam buku ajar Bahasa Indonesia kelas VII Karya Titik Harsiati, Agus Trianto, dan E. Kosasih. Penerbit buku ialah Pusat Kurikulum dan Perbukuan, Balitbang, Kemdikbud. Literasi membaca berdasarkan aspek pemahaman yang meliputi, (a) mengakses dan mengambil informasi dari teks; (b) mengintegrasikan dan menafsirkan; (c) merefleksikan dan mengevaluasi teks dari bacaan buku ajar Bahasa Indonesia. Metode yang digunakan dalam penelitian ini adalah metode deskriptif kualitatif. Hasil penelitian dari keseluruhan isi buku ajar bahasa Indonesia kelas VII yang dianalisis menunjukkan bahwa data literasi telah tersaji dengan lengkap di dalam buku sesuai dengan KI dan KD Kurikulum 2013. Sedangkan pada aspek 3 masih ada data yang tidak terdapat yaitu indikator menyajikan tugas kepada pembaca untuk menilai informasi teks dalam buku ajar dengan sumber lain berdasarkan pengalaman pembaca. Dengan demikian dapat disimpulkan bahwa literasi buku ajar Bahasa Indonesia kelas VII Karya Titik Harsiati, Agus Trianto, dan E. Kosasih yang dianalisis lebih menekankan pada aspek 1 dan 2 yakni menyajikan informasi teks, ide pokok, stuktur, bahasa yang digunakan, pertanyaan yang berkaitan dengan teks, dan pertanyaan yang berkaitan dengan pendapat pribadi siswa.
\end{abstract}

\section{Kata kunci: Buku ajar, literasi.}

\begin{abstract}
Literacy is the ability to access information, understand, identify, express, communicate, and create a work. Therefore, various efforts to improve literacy mastery are needed. This study aims to obtain literacy information in Grade VII Indonesian textbooks at Titik Harsiati, Agus Trianto, and E. Kosasih. Book publishers are the Center for Curriculum and Books, Research and Development, Ministry of Education and Culture. Literacy reads based on aspects of understanding which include, (a) accessing and retrieving information from the text; (b) integrating and interpreting; (c) reflecting and evaluating text from reading Indonesian language textbooks. The method used in this study is a qualitative descriptive method. The results of the research on the entire contents of Indonesian VIL textbooks analyzed indicate that literacy data has been
\end{abstract}


presented in full in the books in accordance with KI and KD Curriculum 2013. Whereas in aspect 3 there is still data that does not exist is an indicator that presents the task to the reader to assess text information in textbooks with other sources based on the experience of the reader. It can be concluded that Titik Harsiati, Agus Trianto and E. Kosasih analyzed emphasize aspects 1 and 2 namely presenting text information, main ideas, structure, language used, questions related to the text, and questions that are literacy in grade VII Indonesian textbooks. The work of Titik Harsiati, Agus Trianto and E. Kosasih relates to students' personal opinions.

\section{Keywords: Teachings book, literacy.}

\section{PENDAHULUAN}

Cita-cita bangsa Indonesia ialah mencerdasakan kehidupan bangsa. Sejalan dengan cita-cita bangsa Indonesia tersebut, maka pendidikan merupakan hal yang harus mendapatkan prioritas. Pendidikan merupakan faktor yang sangat penting bagi kehidupan. Dalam pembangunan nasional, pendidikan diartikan sebagai upaya meningkatkan harkat dan martabat manusia serta dituntut untuk meningkatkan kualitas sumber daya manusia yang lebih tinggi guna menjamin pelaksanaan dan kelangsungan pembangunan. Depdiknas, 2002 (dalam Yamin 2011:326) menyatakan pendidikan beroritentasi pada kecakapan hidup bagi peserta didik adalah sebagai bekal dalam menghadapi dan memecahkan berbagai problema hidup dan kehidupan, baik sebagai pribadi yang mandiri, warga masyarakat, maupun sebagai warga negara.

Sejak 1999 Indonesia ikut dalam proyek penelitian dunia yang dikenal dengan PIRLS (Progress in International Reading Literacy Study), PISA (Program for International Student Assesment), dan TIMSS (the Third International Mathematics and Science Study) untuk mengukur literasi membaca, matematika, dan ilmu pengetahuan alam (Alwasilah, 2012:168). Indonesia merupakan salah satu partisipan PISA (Program for International Student Assesment) di luar negara industri maju yang tergabung dalam OECD (Organization for Ekonomic Cooperation and Development). PISA merupakan salah satu program kerja sama yang dibentuk oleh OECD pada tahun 1997.

Temuan terpenting dari PIRLS (Progress in International Reading Literacy Study) 2006 yang relevan dengan perbincangan tentang literasi membaca, yakni prestasi membaca siswa kelas IV Indonesia masih rendah dibandingkan siswa dari negara lain seperti Maroko, Afrika Utara, Moldavia, dan Singapura (dalam Alwasila, 2012:169). Hal ini sejalan dengan hasil pengukuran yang dilakukan oleh PISA (Program for International Student Assesment) pada tahun 2016 terhadap kemampuan ketiga literasi (membaca, matematika, sains) pada siswa jenjang SMP juga menunjukkan hasil yang sama, bahwa kemampuan siswa Indonesia masih menempati posisi bawah di antara seluruh negara yang diukur.

Memasuki abad ke-21, pembelajaran literasi memiliki tujuan utama untuk memberikan kesempatan atau peluang kepada siswa dalam mengembangkan dirinya sebagai komunikator yang kompeten dalam konteks multiliterasi, multikultural, dan multimedia melalui pemberdayaan multiintelegensi yang 
dimilikinya. Berdasarkan dengan tujuan utama ini, pelajaran literasi pada abad ke21 memiliki tujuan yaitu, membentuk siswa menjadi pembaca, penulis, dan komunikator yang strategis, meningkatkan kemampuan berpikir dan mengembangkan kebiasaan berpikir pada siswa, meningkatkan dan memperdalam motivasi belajar siswa, mengembangkan kemandirian siswa sebagai seorang pemelajar yang kreatif, inovatif, dan berkarakter (The Ontario Ministry of Education, 2006) (dalam Abidin 2017:166). Literasi ialah kemampuan mengakses segala informasi tersirat atau tersurat hingga mampu mengkomunikasikan dan menyebarluaskannya dalam kehidupan. Pembelajaran literasi pada jenjang sekolah menengah pertama (SMP) bertujuan membawa siswa melompat jauh ke depan.

Alwasilah (2012:169) menyatakan skor prestasi membaca di Indonesia adalah 407 (untuk semua siswa), 417 untuk perempuan dan 398 untuk laki-laki. Angkaangka ini di bawah rerata negara peserta, yakni 500, 510, dan 493. Indonesia menempati urutan ke-5 dari bawah, yakni sedikit lebih tinggi dari pada Qatar 356, Kuwait 333, dan Afrika Utara 304. Skor membaca tertinggi diraih oleh Rusia dengan skor prestasi membaca 565, Hongkong 564, Kanada/ Alberta 560, dan Singapura 559.

Di Indonesia hanya tercatat $2 \%$ siswa yang prestasi membacanya masuk ke dalam kategori sangat tinggi, 19\% kategori menengah, dan 55\% masuk ke dalam kategori rendah. Artinya, $45 \%$ siswa di Indonesia tidak dapat mencapai skor 400 dalam membaca. Kita tahu bahwa membaca menduduki peran penting dalam konteks pendidikan manusia terlebih pada era globalisasi, informasi, dan komunikasi seperti sekarang ini. Hal ini disebabkan membaca merupakan sebuah jembatan bagi siapa saja yang berkeinginan meraih kemajuan dan kesuksesan baik di lingkungan pendidikan maupun pekerjaan.

Banyak sekali faktor yang diduga menyebabkan rendahnya literasi membaca anak-anak Indonesia yang berkaitan dengan proses pendidikan. Salah satunya adalah buku ajar. Buku ajar memiliki peran penting dalam pembelajaran bahasa Indonesia. Buku ajar digunakan guru untuk menyampaikan informasi materi pelajaran kepada siswa. Oleh karena itu, analisis terhadap kondisi buku ajar sangat penting dilakukan terutama yang berhubungan dengan analisis literasi membaca. Buku ajar yang dinalisis adalah buku bahasa Indonesia. Untuk dapat memilih buku ajar yang baik diperlukan suatu cara analisis buku yang melibatkan aspek-aspek yang mengandung literasi membaca.

Permasalahan dalam penelitian ini yaitu bagaimana literasi membaca dalam buku ajara bahasa Indonesia karya Titik Harsiati, Agus Trianto, dan E. Kosasih? Tujuan penelitian ini adalah untuk memperoleh informasi literasi membaca dalam buku ajar Bahasa Indonesia kelas VII dengan memperhatikan aspek pemahaman yang meliputi, (a) mengakses dan mengambil informasi dari teks; (b) mengintegrasikan dan menafsirkan; (c) merefleksikan dan mengevaluasi teks dari bacaan buku ajar Bahasa Indonesia kelas VII karya Titik Harsiati, Agus Trianto, dan E. Kosasih.

Peraturan Menteri Pendidikan Nasional Nomor 11 Tahun 2005 (dalam Muslich, 2010:50) menjelaskan bahwa buku teks (buku pelajaran) adalah buku acuan wajib untuk digunakan di sekolah yang memuat materi pembelajaran dalam rangka peningkatan keimanan dan ketaqwaan, budi pekerti dan kepribadian, kemampuan penguasaan ilmu pengetahuan dan teknologi, kepekaan dan kemampuan estetis, serta potensi fisik dan kesehatan yang disusun berdasarkan 
standar nasional pendidikan. Tarigan (1986:11) menyatakan buku teks itu selalu merupakan buku pelajaran yang ditujukan bagi siswa pada jenjang pendidikan tertentu, jadi ada kata lihat buku teks untuk SDM SMP, SMA, dan sebagainya. Wahyu Wibowo (2012:24) menyatakan dewasa ini buku ajar harus dipahami sebagai naskah yang ditulis oleh seorang dosen berkenaan dengan penunjang materi pokok (bacaan wajib) matakuliah yang diajarkannya.

Pakar Literasi, Richard Allington (dalam Mike Schmoker 2012:52) menyatakan era informasi memberikan tuntutan literasi tingkat tinggi kepada kita semua. Tuntutan ini meliputi sintesis dan mengevaluasi informasi dari beragam sumber. Cops dan Kalantzist (dalam Abidin, 2017:5) menyatakatan literasi merupakan elemen terpenting dalam proyek pendidikan modern. Bertemali dengan hal tersebut, alasan utama yang melandasi pengubahan istilah literasi menjadi multiliterasi adalah literasi merupakan desain transformasi yang sangat penting. Warlick (2004:85) menyatakan literasi menggambarkan keterampilan dan pengetahuan kita dalam dalam memanfaatkan usia kita agar sejahtera.

Literasi membaca merupakan memahami, menggunakan, merefleksikan, dan melibatkan diri dalam berbagai jenis teks untuk mencapai suatu tujuan. Dalam hal ini, membaca bertujuan mengembangkan pengetahuan dan potensi seseorang, serta untuk berpatisipasi dalam masyarakat. Berdasarkan definisi ini, membaca diartikan sebagai kegiatan membangun makna, menggunakan informasi dari bacaan secara langsung dalam kehidupan, dan mengaitkan informasi dari teks dengan pengalaman membaca.

PISA (Program for International Student Assessmen) (dalam Abidin, 2017:166) menyatakan atas dasar makna literasi membaca ini penilaian membaca yang dilakukan senantiasa dikemas dalam sebuah tes standar dengan memperhatikan aspek pemahaman. Dalam hal ini, aspek pemahaman yang diuji pun beragam dari tataran sederhana, hingga kompleks, yakni (a) mengakses dan mengambil informasi dari teks, (b) mengintegrasikan dan menafsirkan apa yang dibaca, (c) merefleksi dan mengevaluasi teks, serta menghubungkannya dengan pengalaman pembaca.

\section{METODE}

Metode pada peneitian ini yakni, metode deskriptif kualitatif dan bertujuan untuk memperoleh informasi literasi dalam buku ajar Bahasa Indonesia kelas VII Karya Titik Harsiati, Agus Trianto, dan E. Kosasih yang dianalisis. Data pada penelitian ini berupa materi-materi yang terdapat dalam buku ajar Bahasa Indonesia kelas VII karya Titik Harsiati, Agus Trianto, dan E. Kosasih. Teknik pengumpulan data penelitian ini menggunakan teknik dokumentasi, yaitu pengumpulan data yang telah ada dalam bentuk gambaran, tulisan, atau karya monumental seseorang (Sugiyono, 2006:329). Teknik pengumpulan data dengan cara membaca keseluruhan buku bahasa Indonesia kelas VII karya Titik Harsiati, Agus Trianto, dan E. Kosasih, mengidentifikasi isi materi dan pertanyaan pada setiap $B A B$ buku sesuaikan dengan aspek dan indikator literasi yang dianalisis, memberi kode data kemudian dimasukkan ke dalam kartu data, dan membuat display data pada setiap indikator. Instrumen dalam penelitian ini adalah peneliti itu sendiri. Peneliti sebagai instrumen kunci dalam pelaksanaan penelitian berfungsi menetapkan fokus penelitian, memilih sumber data, melakukan pengumpulan data dan analisis data, menafsirkan data serta membuat kesimpulan (Sugiyono, 2006:306). Teknik analisis data adalah membaca keseluruhan isi buku, 
mengorganisasikan informasi isi buku, membuat kartu data, mengklasifikasikan data ke dalam kartu data, display data, menyimpulkan hasil penelitian.

\section{HASIL DAN PEMBAHASAN}

Berdasarkan analisis data hasil peneltian terhadap literasi buku ajar bahasa Indonesia karya Titik Harsiati, Agus Trianto, dan E. Kosasih telah menerapkan aspek literasi khususnya sapek pemahaman yang meliputi (a) mengakses dan mengambil informasi dari teks; (b) mengintegrasikan dan menafsirkan; (c) merefleksikan dan mengevaluasi teks dari bacaan buku ajar. Namun, pada bagian marefleksikan dan mengevaluasi indikator ke-3 yaitu menyajikan tugas kepada pembaca untuk menilai informasi teks dalam buku ajar dengan sumber lain berdasarkan pengalaman pembaca tidak terdapat karena buku hanya menyajikan jurnal membaca yang di isi pembaca/ siswa berdasarkan hasil bacaannya (buku fiksi/ nonfiksi) dan di isi secara jujur mulai dari judul buku, pengarang, terbitan, waktu baca, ringkasan isi buku, serta komentar

Berikut dipaparkan mengenai hasil dan penelitian:

\section{Aspek Literasi Mengakses dan} Mengambil Informasi dari Teks

a. Menyajikan Informasi Teks yang Jelas sesuai Kebutuhan.
1) Teks deskripsi
2) Teks Narasi (Cerita Fantasi)
3) Teks Prosedur
4) Teks Laporan Hasil Observasi
5) Puisi Raktat
6) Teks Fabel
7) Teks Surat Pribadi dan Surat Dinas
8) Membaca Buku Fiksi dan Nonfiksi

Informasi teks yang ada dalam masing teks tersebut telah tersaji dengan jelas sesuai kebutuhan harus sesuai dengan KI dan KD Kurikulum 2013. Data terkumpul berdasarkan indikator tersebut terdapat pada bab 1 sampai bab 8 menyajikan data informasi teks yang jelas sesuai kebutuhan siswa. Misalnya, pada teks deskripsi mempunyai KD 3.1 Mengidentifikasi informasi dalam teks deskripsi tentang objek (sekolah, tempat wisata, tempat bersejarah, dan atau suasana pentas seni daerah) yang didengar dan dibaca. Informasi yang ada di dalam teks telah terdapat objek tentang pantai yaitu "Parangtritis nan indah, dan Pesona Pantai Senggigi", kemudian terdapat objek suasana pentas seni daerah yaitu "Gebyar Tari Kolosal Ariah". Sebelum memulai untuk memahami informasi terlebih dahulu penulis menuliskan kata-kata yang mengaitkan materi pembelajaran dengan pengalaman siswa/ pembaca seperti "pernahkah kalian menonton televisi tentang seseorang mendeskripsikan suatu objek seperti pantai?" dengan begitu siswa/ pembaca akan mengingat kembali pengalamannya dan akan mulai terhubung dengan materi pembelajaran.

b. Menyajikan Ide Pokok Teks dengan Jelas

1) Teks deskripsi

2) Teks Narasi (Cerita Fantasi)

3) Teks Prosedur

4) Teks Laporan Hasil Observasi

Ide pokok teks yang jelas sesuai kebutuhan harus sesuai dengan $\mathrm{KI}$ dan KD kurikulum 2013. Ide pokok adalah masalah utama yang dibahas dalam suatu paragraf. Nama lain ide pokok adalah pokok pikiran, pikiran pokok, gagasan utama, gagasan pokok, dan pikiran utama. Data terkumpul berdasarkan indikator tersebut ada namun tidak tergolong banyak. Data tidak terdapat pada Bab 5, 6, 7, dan 8. Misalnya, pada teks prosedur memiliki KD 4.5 Menyimpulkan isi teks prosedur tentang cara memainkan alat musik daerah, tarian daerah, cara membuat cinderamata, 
dan/atau kuliner khas daerah) yang dibaca dan didengar. Teks prosedur berjudul "Cara Memainkan Agklung" ide pokoknya terdapat pada kalimat pertama paragraf pertama yaitu Angklung merupakan warisan seni tradisional Indonesia.

c. Menyajikan Struktur Teks dengan Jelas.

1) Teks deskripsi

2) Teks Narasi (Cerita Fantasi)

3) Teks Prosedur

4) Teks Laporan Hasil Observasi

5) Puisi Raktat

6) Teks Fabel

7) Teks Surat Pribadi dan Surat Dinas

Struktur teks ialah bagian-bagian terpisah yang membangun sebuah teks hingga menjadi sebuah teks yang utuh. Struktur teks yang jelas harus sesuai kebutuhan dan KI dan KD kurikulum 2013. Data terkumpul berdasarkan indikator tersebut terdapat pada bab 1 sampai 7 dan tidak terdapat pada bab 8 . Misalnya pada teks narasi (cerita fantasi berjudul "Kekuatan Ekor Biru Nataga" memiliki struktur Judul "Kakuatan Ekor Biru Nataga". Pengenalan/ orientasi latar dan tokoh terdapat pada pargraf 1 dan 2 . Masalah/ komplikasi terdapat pada pargraf 3 dimana pasuka serigala memasuki Pulau Tana Modo. Pemecahan masalah atau resolusi terdapat pada paragraf 8 pada saat Dewi Kabut menyuruh Nataga menggunakan kekuatan ekor birunya dan resolusi terdapat pada paragraf 11 yaitu Nataga menuju bukit bergabung dengan para panglima yang telah berjuang.

d. Bahasa yang Digunakan Relevan dan Mudah Dipahami Pembaca.

1) Teks Deskripsi

2) Teks Narasi (Cerita Fantasi)

3) Teks Surat pribadi dan Surat Dinas.
Bahasa yang digunakan dalam buku bahasa Indonesia kelas VII karya Titik Harsiati, Agus Trianto, dan E. Kosasih relevan dan mudah dipahami pembaca. Namun, peneliti menemukan beberapa kesalahan pada isi buku yaitu kelebihan tanda baca, kesalahan penulisan kata, dan kurangnya huruf dalam suatu kata. Misalnya, pada bab 1 teks deskripsi terdapat kesalahan tidak adanya huruf "p" dalam penulisan "deskripsi" pada halaman 31 bab 1 teks deskripsi terdapat tulisan "Penggunaan Huruf Kapital dan Tanda Koma pada Teks "Deskrisi", yang seharusnya penulisan yang tepat yaitu "Deskripsi".

2. Aspek Literasi Mengintegrasikan dan Menafsirkan Apa yang Dibaca

a. Menyajikan Pertanyaan yang Berkaitan dengan Teks.

1) Teks deskripsi

2) Teks Narasi (Cerita Fantasi)

3) Teks Prosedur

4) Teks Laporan Hasil Observasi

5) Puisi Raktat

6) Teks Fabel

7) Teks Surat Pribadi dan Surat Dinas

8) Membaca Buku Fiksi dan Nonfiksi

Menyajikan pertanyaan yang berkaitan dengan teks harus sesuai dengan KI dan KD kurikulum 2013. Data terkumpul berdasarkan indikator tersebut jumlahnya banyak mulai dari bab 1 sampai bab 8 . Misalnya, pada teks prosedur memiliki KD 3.5 Mengidentifikasi teks prosedur tentang cara melakukan sesuatu dan cara membuat (cara memainkan alat musik/tarian daerah, cara membuat kuliner khas daerah, dll.) dari berbagai sumber yang dibaca dan didengar. Pertanyaan yang berkaitan dengan teks yaitu Mengidentifikasi ciri teks prosedur. Kemudian Mengidentifikasi tujuan teks 
prosedur 1, 2 dan 3. Pertanyaan berkaitan dengan teks prosedur berjudul "Cara Memainkan Angklung", "Cara Membuat Obat Tradisional Insomnia", dan "Cara Melakukan Gerakan Tari Tor-tor". Pembaca akan mengeluarkan keterampilannya menjawab pertanyaan sesuai dengan teks yang telah dibaca.

b. Menyajikan Pertanyaan yang Berkaitan dengan Pendapat Pribadi Pembaca Tentang Teks yang Telah Dipahami.

1) Teks deskripsi

2) Teks Narasi (Cerita Fantasi)

3) Teks Prosedur

4) Teks Laporan Hasil Observasi

5) Puisi Raktat

6) Teks Fabel

7) Teks Surat Pribadi dan Surat Dinas

8) Membaca Buku Fiksi dan Nonfiksi

Menyajikan pertanyaan yang berkaitan dengan pendapat pribadi pembaca tentang teks yang telah dipahami harus sesuai dengan KI dan KD kurikulum 2013. Data pertanyaan yang berkaitan dengan pendapat pribadi pembaca tentang teks yang telah dipahami terdapat dalam buku bahasa Indonesia kelas VII karya Titik Harsiati, Agus Trianto, dan E. Kosasih berdasarkan indikator tersebut jumlahnya banyak mulai dari bab 1 sampai bab 8 . Misalnya pada KD 4.1 Menjelaskan isi teks deskripsi objek (tempat wisata, tempat bersejarah, pentas seni daerah, kain tradisional, dll) yang didengar dan dibaca secara lisan, tulis, dan visual. Pertanyaan yang berkaitan dengan pendapat pribadi pembaca tentang teks yang telah dipahami yaitu (a)apa yang dibicarakan penulis pada teks 1 dan 2? (b) keindahan bagaian mana saja dari pantai Senggigi dan apa saja yang dijelaskan penulis tentang pementasan tari kolosal Ariah dari awal pementasan sampai akhir pementasan? (c) apa tujuan penulis menampilkan teks di atas? (d) Bagaimana penulis menggambarkan keindahan pantai Senggigi dan keindahan pementasan tari kolosal ariah. Serta berikan alasan untuk mendukung jawabanmu!. Pertanyaan dijawab bedasarkan pemahaman sendiri (pembaca) terhadap 2 teks deskripsi yang berjudul "Pesona Pantai Senggigi", dan "Gebyar Pementasan Tari Kolosal Ariah". Penulis membuat pertanyaan tersebut agar pembaca mengeluarkan kemampuannya dalam menafsirkan teks berdasarkan pemahamannya, dan dapat menjelaskan perbedaan dari kedua isi teks deskripsi.

\section{Merefleksikan dan Mengevaluasi teks.}

a. Menyajikan Informasi Teks/ Tugas yang Berhubungan dengan Pengalaman Pembaca.
1) Teks Narasi
2) Teks Prosedur
3) Teks Fabel

Menyajikan tugas yang berkaitan dengan informasi teks/ tugas yang berhubungan dengan pengalaman pembaca harus sesuai dengan KI dan KD kurikulum 2013. Tugas yang berkaitan dengan informasi teks/ tugas yang berhubungan dengan pengalaman pembaca terdapat pada bab 2, 3 dan 6 dan tidak terdapat pada bab 1, 4, 5, 7, dan 8 .

b. Menyajikan Tugas Kepada Pembaca Untuk Menilai Karya Sendiri/ Orang Lain yang Diciptakan Berdasarkan Pengalaman.

1) Teks deskripsi

2) Teks Narasi (Cerita Fantasi)

3) Teks Prosedur

4) Teks Laporan Hasil Observasi

5) Puisi Raktat

6) Teks Fabel

Menyajikan tugas kepada pembaca untuk menilai karya sendiri/ orang lain 
yang diciptakan berdasarkan pengalaman harus sesuai dengan $\mathrm{KI}$ dan KD kurikulum 2013. Data berupa tugas terdapat dalam buku bahasa Indonesia kelas VII karya Titik Harsiati, Agus Trianto, dan E. Kosasih pada bab 1 sampai 6. Namun, data tidak terdapat pada bab 7 dan 8 .

\section{c. Menyajikan Tugas/ Kesempatan pada Pembaca untuk Menilai Informasi Teks yang terdapat dalam Buku dengan Sumber lain/ Pengalaman Pembaca}

Data berdasarkan indikator tersebut tidak terdapat dalam buku bahasa Indonesia kelas VII karya Titik Harsiati, Agus Trianto, dan E. Kosasih.

Secara keseluruhan isi materi setiap bab dalam buku bahasa Indonesia kelas VII karya Titik Harsiati, Agus Trianto, dan E. Kosasih telah memaparkan aspek literasi beserta indikatornya. Informsi sesuai dengan kebutuhan siswa yakni sesuai Kurikulum 2013, pertanyaan dan tugas yang terdapat dalam buku berkaitan dengan kehidupan sehari-hari siswa/ pembaca, berkaitan dengan pendapat pibadi siswa/ pembaca sehingga pembaca dapat dengan mudah mengerjakan pertanyaan dan tugas yang ada dalam buku. Dalam buku penulis juga membekali pembaca dengan kata-kata motivasi sebelum menjawab pertanyaan dan sesudah menjawab pertanyaan serta cakupan lingkungan belajar untuk jenjang SMP yang ditulis penulis dalam buku telah mencakup Nasional dengan isi informasi buku telah mencakup informasi yang ada di Indonesia.

\section{PENUTUP}

\section{Kesimpulan}

Berdasarkan hasil penelitian dan pembahasan yang ada dapat disimpulkan bahwa literasi membaca berdasarkan aspek pemahaman yang meliputi, (a) mengakses dan mengambil informasi dari teks; (b) mengintegrasikan dan menafsirkan; (c) merefleksikan dan mengevaluasi teks, telah menerapkan aspek literasi sesuai dengan $\mathrm{KI}$ dan KD kurikulum 2013 dan kebutuhan siswa SMP dalam belajar yaitu dapat mengakses informasi dengan membaca isi buku, memahami, mengekspresikan, mengkomunikasikan dan menciptakan karya hasil ciptaannya sendiri. Cakupan lingkungan belajar jenjang SMP mencakup Nasional dan isi materi buku ajar bahasa Indonesia kelas VII karya Titik Harsiati, Agus Trianto, dan E. Kosasih telah mencakup semua informasi yang ada di Indonesia. Namun, masih terdapat kekurangan pada bagian merefleksikan dan mengevaluasi khususnya indikator 3 tidak ada data yang menyajikan tugas kepada pembaca/ siswa untuk menilai informasi yang terdapat dalam buku dengan sumber lain yang pernah dibaca berdasarkan pengalaman pembaca/ siswa itu sendiri. Di dalam buku hanya terdapat "Jurnal Membaca" pada akhir setiap bab buku yang menyarankan siswa untuk menulis ringkasan buku fiksi yang dibaca siswa sesudah/sebelum belajar.

\section{Saran}

Berdasarkan hasil simpulan dan pembahasan yang telah dilakukan, maka penulis mengajukan saran agar buku bahasa Indonesia kelas VII karya Titik Harsiati, Agus Trianto, dan E. Kosasih terbitan Pusat Kurikulum untuk menambahkan tugas/ kegiatan kepada siswa dalam menilai sendiri isi materi buku ajar bahasa Indonesia kelas VII dengan sumber lain yang pernah dibaca siswa berdasarkan pengalamannya agar lebih menambah pengetahuan siswa tentang isi materi buku ajar bahasa Indonesia dengan isi materi sumber bacaan lain yang pernah dibaca sebelumnya sesuai dengan kebutuhan siswa. 
DAFTAR PUSTAKA

Abidin Y., Mulyati., dan Yunansah. 2017. Pembelajaran Literasi. Jakarta: Bumi Aksara.

Alwasilah, C. 2012. Pokoknya Rekayasa Literasi. Bandung: PT Kiblat Buku Utama.

Harsiati T., Trianto, Agus., dan Kosasih. 2016. Bahasa Indonesia. Jakarta: Kemdikbud.

Muslich, M. 2010. Metode Text Book Writing. Jogjakarta: Ar-Ruzz Media.

Sugiyono. 2006. Metode Penelitian Pendidikan. Bandung: Alfabeta Bandung.
Schmoker, Mike. 2012. Menjadi Guru yang Efektif. Jakarta: Erlangga.

Tarigan, HG., dan Djago Tarigan.1986. Telaah Buku Teks Bahasa Indoensia. Bandung: Angkasa Bandung.

Wibowo, Wahyu. 2012. Menulis Buku Ajar Perguruan Tinggi. Jakarta: Bidik Phronesis Publishing.

Warlick, Dafid. 2004.Redefining Literacy for 21th Century. Ohio: Limworth.

Yamin, Martinis. 2011. Paradigma Baru Pembelajaran. Jakarta: GP Press. 